http://jmscr.igmpublication.org/home/ ISSN (e)-2347-176x ISSN (p) 2455-0450 crossref DOI: https://dx.doi.org/10.18535/jmscr/v7i11.169

\author{
Dournal Of Medical Science And Clinical Research \\ IGM Publication \\ An Official Publication of IGM Publication
}

\title{
External Fixation versus Unreamed Interlocking Intramedullary Nailing for Open Tibia Fracture
}

\author{
Authors \\ Mabrouk S. Bohalfaya*, Ali B. Hamad \\ *Corresponding Author \\ Dr Mabrouk S. Bohalfaya
}

M.D. Arab Board, M.D. Libyan Board Orthopedics, Assistant Professor Faculty of Medicine Benghazi

University - Benghazi, Hawari General Hospital, Orthopedic Department.

\begin{abstract}
Open fractures of tibia are more common in active adults due to direct trauma, and they pose a major therapeutic challenge due to high incidence of postoperative complications. Although locked unreamed intramedullary nail (IMN) and external fixator (EF) are the most common treatment modalities, the superior mode of management remains controversial. The purpose of this study was to compare the outcome of open tibial shaft fractures in adults treated with locked undreamed conducted in orthopaedic department at Almarj Teaching Hospital for a period of twenty four months from June 2014 to June 2016.In this study, fifty-six open tibia shaft fractures in fifty-four patients were divided into two groups, twenty five fractures were treated by unreamed locked IMN, and thirty one fractures were treated by EF. Thirty six fractures were due to gunshot wound and explosive injury, ten were due to RTA, and ten were due to indirect trauma. According to Anderson Gustilo classification eleven fractures were type I, sixteen were type II, and twenty nine were type III. All cases were prospectively followed for twenty four months. The rate of union, soft tissues healing, and any complication were recorded. To analyze the results a chi square test and an SPSS software were used to study the significant relation and association between multiple variables of these two groups. Nineteen fractures healed uneventfully seven of EF group and twelve of IMN group, ten fractures had superficial infection seven of EF group and three of IMN group, four fractures developed deep infection all were EF group, four fractures had malunion two of EF group and two of IMN, six fractures had delayed union two of EF group and four of IMN group, five fractures had nonunion threeof EF group and two of IMN group, three fractures ended with amputation all were EF group, two fractures had broken distal locking screws, and three fractures were exchanged from EF into IMN.

Locked unreamed intramedullary nail (IMN) appears to be a better option for the treatment of Gustilo type I, II, and IIIA open tibial shaft fractures compared to external fixator as it shows less complication rate.

Keywords: Tibia fractures, Intramedullary nails, External fixator.
\end{abstract}

\section{Introduction}

Open fractures of the tibia are among the most difficult to treat, due to poor soft tissue cover and blood supply of the tibial shaft. The extent of the soft tissue injury and the amount of comminution are directly related to the level of energy causing the fracture. Once quantified, the importance of soft tissue damage as an important predictor of infection and poor outcome, has since been confirmed $^{[1-7]}$ Tibia is the most common long bone to sustain an open fracture, which is significant given the precarious superficial position of its 
blood supply ${ }^{[8-11]}$. These fractures are showing an increasing trend due to road traffic accidents and firearm (war) injuries ${ }^{[12]}$, these injuries are on the rise in last few years in Libya due to increasing incidence of gunshot, shotgun, and road traffic accident, and their management is a common problem in trauma centers. The soft tissue management is the most important factor in determining the outcome of open tibia fractures with the optimal method of fixation is still debated. Sufficient stability of the fracture fragments and soft tissues usually can be obtained only by locked intramedullary nail or external fixator $^{[13]}$, and this continues to be a major therapeutic problem because of poor soft tissue cover and blood supply of the tibial shaft which make these fractures vulnerable to nonunion and infection $^{[14]}$.

Preventing tibia from postoperative infection, obtaining union, and returning the involved limb to normal function always remain elusive goals. External fixation and locked unreamed intramedullary nailing are two common approaches for fixation of open tibia fractures. Initially, the management by EF is well established as it allows immediate stabilization with access for management of the soft tissues. However, its use is also associated with significant rates of malunion and pin tract infection often necessitating premature removal and conversion to alternate forms of stabilization [15-19].

In most large series of grade-III fractures treated in this way, external fixation has been used to stabilize the fracture, relatively to avoid further damage to the blood supply of bone which would be caused by reaming. Most of these severe injuries are too comminuted to allow use of unlocked intramedullary nails. However small diameter interlocking intramedullary tibial nail which can be placed without reaming, has provided a new method for stabilization of these fractures $^{[20]}$.

Currently, many traumatologists prefer intramedullary nailing for Gustilo type I, type II and type IIIA open fractures, although equipment for nailing in resource-limited environments may make it difficult to perform ${ }^{[21]}$.

External fixation has been popular because of ease of application and limited effect on blood supply of the tibia, but these advantages have been outweighed by the high incidence of pin-track infection, difficulties related to soft tissue management and the potential for malunion, delayed union and nonunion ${ }^{[22,23]}$. Thus, the current recommended treatment for type IIIA open tibia shaft fracture can be either; surgical debridement and fixation by interlocking intramedullary nail or surgical debridement and fixation by external fixation. With respect to recovery from tibial shaft fractures, the most salient outcomes include callus formation, infection, and malalignment and shortening. Existing literature suggests that IM nailing can lead to bridging callus at the fracture as early as three months ${ }^{[24]}$. Although EF and IMN have been used as treatments of choice for tibia fractures, which of them can be served as an optimal approach still uncertain. There were some previous analyses which supported the use of unreamed IMN for open tibia fractures. However, the outcomes in recently published articles still remain controversial ${ }^{[25-29]}$. Type III open tibia fractures are associated with high rates of infection, nonunion, malunion, and amputation. Infection rates in these fractures are reported to be much higher than those for type-I and type-II fractures. Infection rates for types I, II and III of $0-2 \%, 2-7 \%$, and $10-50 \%$ have been recorded respectively ${ }^{[30-32]}$.

The increasing use of immediate antibiotics, aggressive and repeated debridement, fracture stabilization, early bony coverage, and prophylactic bone grafting has greatly reduced the rates of infection and nonunion ${ }^{[33-73]}$. In addition, there have been reports that IM nailing for type IIIA open tibia fractures can lead to an infection rate as low as $5.5 \%$, while other reports show that EF infection rate may be as high as $26.4 \%^{[38,39]}$. Finally, open tibia patients are at risk of a 
shortened and malaligned leg after recovery ${ }^{[40]}$. In addition, IMN allows stable fixation with minimal additional violation of the soft tissues in the region of the fracture via placement of unreamed or reamed interlocking nails. The use of IMN in treating open tibial shaft fractures results in a high rate of union and a low rate of infection and mansion $^{[41-45]}$.

Meanwhile, great benefits of EF for the fixation of open tibia fractures have been observed in shortening operation time, reducing blood loss and soft tissue injury, and improving blood supply at the broken ends and facture healing rate $e^{[41-45]}$.

In this study a comparison has been done between external fixation and unreamed interlocked intramedullary tibial nailing for management of open fracture types I, II, and IIIA of tibia in adults. We conducted an updated meta-analysis with all the relevant studies to provide reliable evidence for the better efficacy of IMN approach than EF in the fixation of open tibia fractures.

\section{Materials and Methods}

This study was conducted in orthopedic department at Almarj Teaching Hospital for a period of twenty four months from June 2014 to June 2016.In this study, fifty-six open tibia shaft fractures in fifty-four patients were divided into two groups, twenty five fractures were treated by unreamed locked IMN, and thirty one fractures were treated by EF. All cases were prospectively followed for twenty four months. The rate of union, malunion, delayed union, nonunion, soft tissues healing, hardware failure, and any other complication were recorded. To analyze the results a chi square test and an SPSS software were used to study the significant relation and association between multiple variables of these two groups.

\section{Inclusion criteria}

1) Patients with open tibia fractures, and the diagnosis was clearly defined.

2) Treatment by IMN and EF, and no other method of treatment.
3) Outcomes were accessed by at least one of the following indicators including postoperative infection, malunion, nonunion, amputation, and hardware failure.

4) Follow-up duration was more than eighteen months.

5) One surgeon performed all the operations. Exclusion Criteria: Fractures located within $5 \mathrm{~cm}$ of the proximal or distal articular surface, fractures extending into a joint, and patients less than 16 years old. Data was extracted from patients' admission files and follow up data. The detailed data included sample size, gender and age of patients, mechanism of fracture, type of tibia fracture, and method of fixation. The indicators including postoperative infection, malunion, nonunion, amputation, and hardware failure were used for quantitative outcome assessment. To analyze results a chi square test and SPSS software were used to study significant relation and association between multiple variables of the two study groups.

\section{Results}

Out of fifty six fractures in fifty four patients forty eight were males and eight were females, twenty five were treated by IMN ( $\mathrm{M}=22 ; \mathrm{F}=3)$, and thirty one by $\mathrm{EF}(\mathrm{M}=26 ; \mathrm{F}=5)$, forty six were due to direct trauma $(\mathrm{M}=38 ; \mathrm{F}=8)$ with nine Gustilo type I, fourteen Gustilotype II, and twenty three Gustilo type III (EF=26; IMN=20), and ten fractures were due to indirect trauma (all males) with two Gustilo type I, two Gustilo type II, and six Gustilo type III (EF=5; IMN=5). Nineteen fractures developed no complications (EF7; $\mathrm{IMN}=12$ ), ten fractures developed superficial infection $(\mathrm{EF}=7 ; \quad \mathrm{IMN}=3)$, four fractures developed deep infection ( $\mathrm{EF}=4 ; \mathrm{IMN}=0)$, four fractures developed malunion $(\mathrm{EF}=2 ; \mathrm{IMN}=2)$, six fractures developed delayed union $(\mathrm{EF}=2$; $\mathrm{IMN}=4$ ), five fractures developed nonunion $(\mathrm{EF}=3 ; \mathrm{IMN}=2)$, three fractureshad amputation $(\mathrm{EF}=3 ; \quad \mathrm{IMN}=0)$, two fractures developed hardware failure as broken screw $(\mathrm{EF}=0$; 


\section{JMSCR Vol||07||Issue||11||Page 974-981||November}

$\mathrm{IMN}=2$ ), and three fractures were revised $(\mathrm{EF}=3 ; \mathrm{IMN}=0)$. The incidence of postoperative infection (deep and superficial) was reported in fourteen fractures $(\mathrm{EF}=11 ; \mathrm{IMN}=3)$. Four fractures had malunion $(\mathrm{EF}=2 ; \mathrm{IMN}=2)$, delayed union was seen in six fractures $(\mathrm{EF}=2 ; \mathrm{IMN}=4)$, nonunion was noticed in five fractures $(\mathrm{EF}=3$; $\mathrm{IMN}=2$ ), three fractures ended with amputation $(\mathrm{EF}=3 ; \mathrm{IMN}=0)$, and hardware failure was seen in two fractures $(\mathrm{EF}=0 ; \quad \mathrm{IMN}=2)$. The frequencies variables of our study included: IAge: The most common affected age of open tibia fractures is 25years (17.9\%).II-Sex: The most common affected sex is the male (85.7\%).IIITreatment protocol: Most of open tibia fractures are treated by $\mathrm{EF}(55.4 \%)$. IV-Complications: Most cases of open tibia fracture developed no complication (33.9\%).V- Fracture type: The most common type of open tibia fractures is Gustilo III A $(51.8 \%)$.

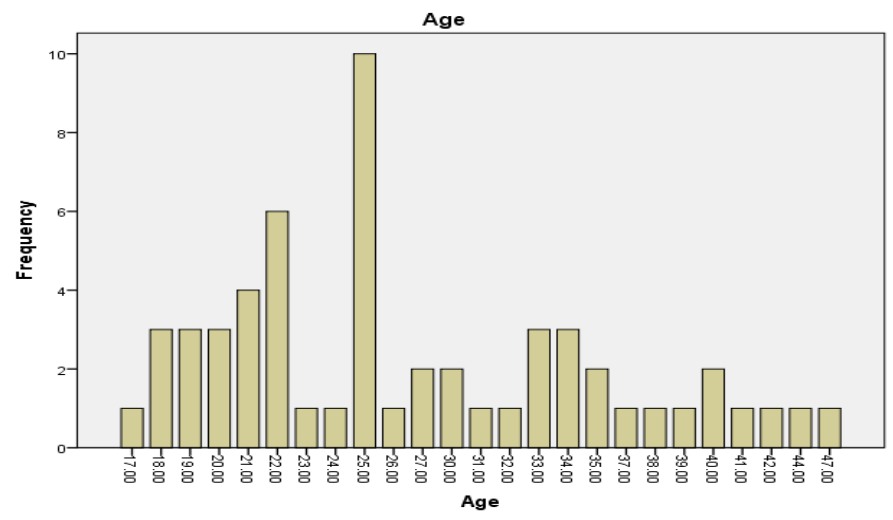

Fig. (9) Age frequency, the most common affected age of open tibia fractures is 25years $(17.9 \%)$.

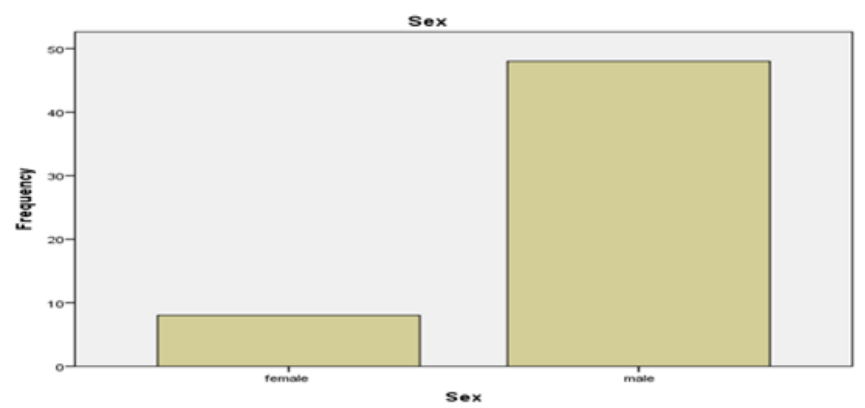

Fig. (10) Sex frequency, the most common affected sex by open tibia fractures is the male $(85.7 \%)$.

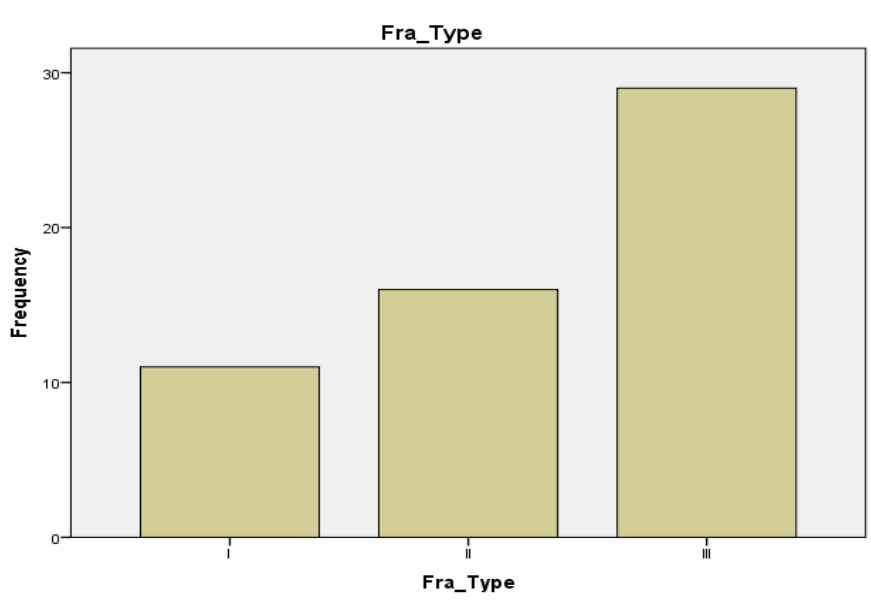

Fig. (11) Fracture types frequency, the most common type of open tibia fractures is IIIA $(51.8 \%)$.

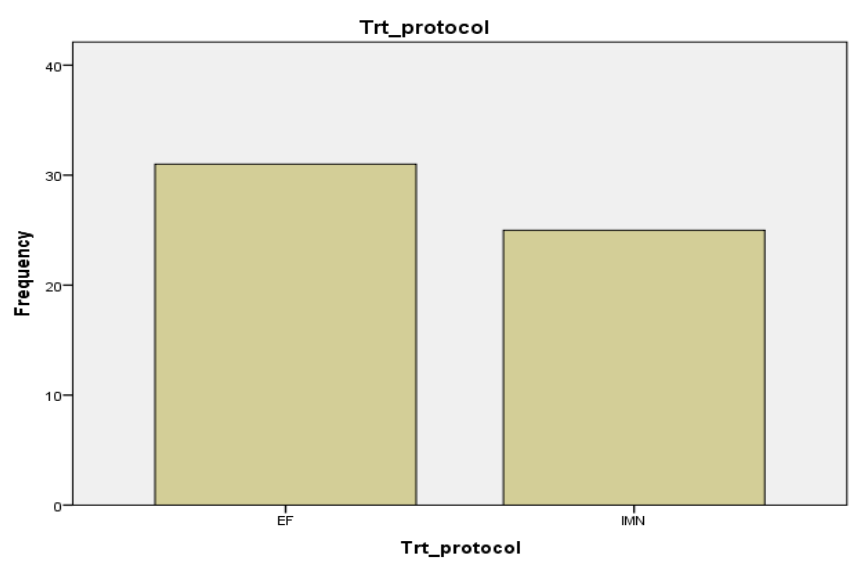

Fig. (12) Treatment frequency, the most of open tibia fractures is treated by $\mathrm{EF}(55.4 \%)$.

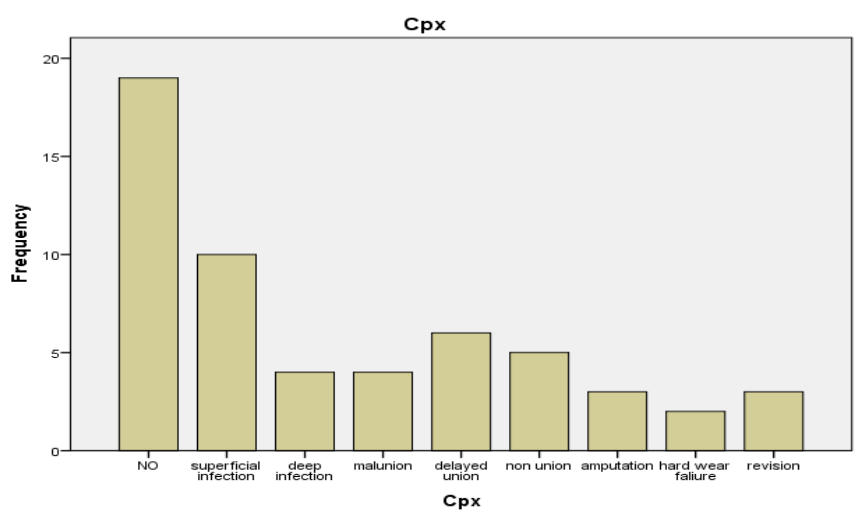

Fig. (13) Complications frequency, the most cases of open tibia fracture developed no complication $(33.9 \%)$.

\section{Discussion}

The accepted protocols for managing open tibia fractures include immediate debridement and 
irrigation, administration of antibiotics, skeletal stabilization, delayed wound closure, and early soft tissue coverage. Postoperative infection is an important factor for predicting patient prognosis in terms of limb salvage and preservation of function. One of the basic goals in the treatment of open tibia fractures is to prevent infection. Previous studies have indicated that IMN may increase the risk of deep infections and even the risk of amputation. However, in this study the results indicate that the incidence of postoperative infection in patients treated with EF approach was significantly higher than that in patients treated with IMN approach $(\mathrm{P}=.0530)$."Kaftandziev et al. have noted that sterile metal does not cause infection but that sterile metal combined with inadequate debridement or absent soft tissue coverage does lead to infection in devitalized soft tissue and bone. An important factor in the body's ability to resist infection is the viability of surrounding soft tissue. Consequently, adequate debridement and early soft tissue coverage may be the keys to preventing deep infections and producing favorable results. ${ }^{\text {"[50] }}$.

Four fractures had malunion $(\mathrm{EF}=2 ; \mathrm{IMN}=2)$, indicating that occurrence of malunion was not different between IMN and EF. Some published studies have reported that open tibia fracture patients treated with EF may experience malunion, with an incidence of up to $20 \%{ }^{[51,52]}$. In contrast, the IMN is much closer to the fracture site, it can provide robust stability and therefore effectively maintain alignment, which could contribute to the lower incidence of malunion. Delayed union was evaluated in six fractures $(\mathrm{EF}=2 ; \mathrm{IMN}=4)$, indicating that the incidence of delayed union was reduced by EF more than by IMN."However, in some other previous studies, the healing bone cannot distinguish between correct and incorrect alignment patterns. Once the healing process begins, final bone healing can be achieved in both groups despite the alignment condition $^{[53]}$. Clinically nonunion was seen in five fractures $(\mathrm{EF}=3 ; \mathrm{IMN}=2)$, indicating that the incidence of nonunion was reduced by IMN compared to EF.

Three fractures ended with amputation $(\mathrm{EF}=3$; $\mathrm{IMN}=0$ ), indicating that the incidence of amputation was reduced by IMN compared to EF. Hardware failure was evaluated in two fractures $(\mathrm{EF}=0 ; \mathrm{IMN}=2)$, indicating that the incidence of hardware failure was reduced by EF compared to IMN." Hardware failure remains the most reported complication of IMN, with an incidence of up to 3-16\%. The most common hardware failure is the breakage of locking screws. However, Alberts et al.'s research showed that locking screw failure's long-term effect is minor because in most cases this complication could not be noticed in the first eight weeks and did not result in more than $5 \mathrm{~mm}$ of shortening. Generally speaking, these failures are related to fracture patterns, fracture locations and the patients' weight bearing statuses. Unlike the compound system of nail and bone in reamed nails, IMN functions as a splint in the medullary cavity. The load is transmitted directly to the locking screws. Awareness of this function and adherence to a strict protocol concerning patient mobilization and weight-bearing status appear to be the most important factors for avoiding this kind of failure. ${ }^{\prime[54-56]}$. However, there is no consensus on the best method of bony stabilization. EF and IMN are two well-accepted techniques, and they are also associated with the most controversy over which is the optimal treatment. The functional outcome is also a focus after fracture surgery. An obvious advantage of IMN is that is can allow for early range of motion after surgical intervention. In contrast the EF technique where passing of wires and pins through muscles may limit motion and lead to joint contracture ${ }^{[57,58]}$.

According to our study, IMN reduced the incidence of superficial infection, nonunion, and malunion compared to EF. However, EF had a significantly lower rate of hardware failure, postoperative deep infection, and delayed union. Our study has some limitations, such as small number of cases, lack of regular follow up, lack of 
treatment cost evaluation, lack of enough data and the surgeons' experience, all of these may have influenced the results. The results indicated that the patients treated by IMN had lower incidence of postoperative complications compared to those treated by EF. The superiority of IMN was more comprehensively proved by this analysis. For the most clinical endpoints studied in this analysis, IMN group has considerably higher efficacy for treatment of open tibia fractures compared to EF group. The IMN can offer stability and anatomic alignment of the affected bone, even in the presence of bone loss or comminution.

\section{Conclusion}

Locked unreamed intramedullary nail (IMN) approach appears to be a better option for the treatment of Gustilo type I, II, and IIIA open tibial shaft fractures as compared to external fixator. Advantages of the IMN include less rate of complications like nonunion, infection, amputation, and revision.

We recommend to use it as a first-line treatment for patients with open type I, II, and IIIA tibia fractures.

\section{References}

1. Gustilo, Ramon B., Rex M. Mendoza, and David N. Williams. "Problems management of type III (severe) open fractures: a new classification of type III fractures." Journal of Trauma and Acute Care Surgery 24.8 (1984): 742-746.

2. Rosenthal, Ronald E., J. A. MacPhail, and J. E. Oritz. "Non-union in open tibia fractures." JBJS 59.2 (1977): 244-248.

3. Waddell J. P., and G. P. Reardon. "Atlantoaxial arthrodesis to treat odontoid fractures." Journal canadien de chirurgie 26.3 (1983): 255-7.

4. Yaremchuk, Michael J., et al. "Acute and definitive management of traumatic osteocutaneous defects of the lower extremity." Plastic and reconstructive surgery 80.1 (1987): 1-12.
5. Caudle, Robert J., and P. J. Stern. "Severe open fractures of the tibia." JBJS 69.6 (1987): 801-807

6. Edwards, Charles C., et al. "Results Treating 202 Injuries with External Fixation." Clinical orthopaedics and related research 230 (1988): 98-115.7.

7. Fischer, Mark D., R. B. Gustilo, and T. F. Varecka. "The timing of flap coverage, bone grafting, and intramedullary nailing in patients who have a fracture of the tibial shaft with extensive soft-tissue injury." JBJS 73.9 (1991): 1316-1322.

8. Wheelwright E, Christie J, Mcqueen M. External fixation for type III open tibia fractures. J Bone Joint Surg (Br) 1990;72:801-804.

9. Nork SE, Schwartz AK, Agel J, Holt SK, Schrick JL, Winquist RA. Intramedullary nailing of distal metaphysealtibial fractures. J Bone Joint Surg (Br) 2005;87:1213- 1221.

10. Randomized trial of reamed and unreamed intramedullary nailing of tibial shaft fractures. J Bone Joint Surg Am. 2008;90:2567.

11. Kakar S, Tornetta P III. Open fractures of the tibia treated by immediate intramedullary tibial nail insertion without reaming: a prospective study. J Orthop Trauma. 2007;21:153-157.

12. Chummy Sinnatamby. Last's Anatomy. $12^{\text {th }}$ ed. Elsevier Ltd; Churchill Livingstone; 2011.

13. Abdelaal MA, Kareem S. Open fracture tibia treated by unreamed interlocking nail. Long experience in El-Bakry General Hospital. Open J Orthoped. 2014;4:60- 69.

14. Hoppenfeld, Stanley, deBoer, Piet, Buckley, Richard. Surgical Exposures in Orthopaedics: The Anatomic Approach. 4th ed. Lippincott Williams \& Wilkins; 2009.

15. Henry Gray, Susan Standring. Gray's Anatomy. 39th ed Edinburgh; Churchill 
Livingstone; 2008.

16. Frassica Frank J.,Sponseller, Paul D.; Wilckens, John H. 5-Minute Orthopedic Consult. 2nd ed. Lippincott Williams \& Wilkins; 2007.

17. Kenneth A.,Egol, Kenneth J. Koval, Joseph D. Zuckerman. Handbook of fractures. $5^{\mathrm{TH}}$ ed.Wolters Kluwer Health; 2015.

18. Gustilo, Ramon B., Robert P. Gruninger, and Tracy Davis. "Classification of type III (severe) open fractures relative to treatment and results." Orthopedics 10.12 (1987): 1781-1788.

19. Irfanullah, K., Shahzad, J., Gauhar, N.K. and Amer, A. Outcome of intramedullary interlocking SIGN nail in tibialdiaphyseal fracture. J Coll Physicians Surg Pakistan. 2013; 23(3):203-207.

20. Noumi T, Yokoyama K, Ohtsuka H, Nakamura K, Itoman M. Intramedullary nailing for open fractures of the femoral shaft: evaluation of contributing factors on deep infection and nonunion using multivariateanalysis. Injury. 2005;36:1085 1093.

21. Olson, S.A., Willis, M.D. Editors. Initial management of open fractures: Lippincott Williams \& Wilkins; 2006.

22. Court-Brown, C.M., Wheelwright, E.F., Christie, J. and McQueen, M.M. External fixation for type III open tibia fractures. J Bone Jt Surg. 1990; 72:801-804.

23. Zirkle, L.G. Technique manual of SIGN IM nail \& interlocking screw system insertion \& extraction guide. Available from: www.signfracturecare.org

24. Rommens P, Van Raemdonck D, Broos P. Reosteosynthesis of the tibial shaft. Part I. Changeof procedure after external fixation. ActaChir Belg. 1988;89:281-286.

25. Bråten $\mathrm{M}$, Helland $\mathrm{P}$, Grøntvedt $\mathrm{T}$, Aamodt A, Benum P, Mølster A. External fixation versus locked intramedullary nailing in tibial shaft fractures: a prospective, randomised study of 78 patients. Arch Orthop Trauma Surg. 2005;125:21-26.

26. Helland P, Bøe A, Mølster AO, Solheim E, Hordvik M. Open tibial fractures treated with the Ex-fi-re external fixation system. Clin Orthop Relat Res. 1996;326:209-220.

27. Emami A, Mjöberg B, Karlström G, Larsson S. Treatment of closed tibial shaft fractures with unilateral external fixation. Injury. 1995;26:299-303.

28. El-Sayed M, Atef A. Management of simple (types A and B) closed tibial shaft fractures using percutaneous lag-screw fixation and Ilizarov external fixation in adults. IntOrthop. 2012;36:2133-2138.

29. Olson, S.A., Schemitsch, E.H. Open fractures of the tibial shaft: an update. Instr Course Lect. 2003; 52:623-631.

30. Canale, S.T., Beaty, J.H. Campbell's operative orthopaedics 11th ed. USA: Mosby Elsevier. 2007.

31. Mcharo, C.N., Museru, L.M., Assey, A.B. The incidence and treatment outcome of open fractures of the extremities at MOI. Tanzania Med J. 2005; 20(1):19-21.

32. Velazco, A. and Fleming, L.L. Open fractures of the tibia treated by the Hoffmann external fixator. Clin. Orthop. Relat. Res. 1983; 180:125-132.

33. Blick SS, Brumback RJ, Lakatos R, Porn A, Burgess AR. Early prophylactic bone grafting of high-energy tibial fractures. Clin Orthop Relat Res. 1989;240:21-41.

34. Beltsios M., Savvidou O., Kovanis J., Alexandropoulos P. and Papagelopoulos P. External fixation as a primary and definitive treatment for tibialdiaphyseal fractures. Strateg Trauma Limb Reconstr. 2009; 4(2):81-87.

35. PunoR.M., Teynor J.T., Nagano J. and Gustilo R.B. Critical analysis of results of treatment of 201 tibial shaft fractures. ClinOrthopRelat Res. 1986; 212:113-121. 
36. WHO. Injury: a leading cause of the global burden of disease. 2000.

37. Olson, S.A. Open fractures of the tibial shaft. Instr. Course Lect. 1997; 46:293302.

38. Behairy YM, Al-Balla AS. Open tibial fractures. Saudi Med J. 2006;27:745- 746.

39. Giannoudis P, Papakostidis C, Roberts C. A review of the management of open fractures of the tibia and femur. J Bone Joint Surg (Br) 2006;88:281-289.

40. Gustilo, Ramon B., Robert L. Merkow, and D. A.V.I.D. Templeman. "The management of open fractures." JBJS 72.2 (1990): 299-304.

41. Edwards and Charles C. "Staged Reconstruction of Complex Open Tibia Fractures Using Hoffmann External Fixation: Clinical Decisions and Dilemmas." Clinical orthopaedics and related research 178 (1983): 130-161.

42. Patzakis, Michael J., Jeanette Wilkins, and Tillman M. Moore. "Considerations in reducing the infection rate in open tibial fractures." Clinical orthopaedics and related research 178 (1983): 36-41.

43. Blick, Samuel S., et al. "Early prophylactic bone grafting of high-energy tibia fractures." Clinical orthopedics and related research 240 (1989): 21-41.

44. Bach, Allan W., Sigvard T. Hansen JR. "Plates versus external fixation insevere open tibial shaft fractures.": a randomized trial. Clinical orthopedics and related research 241 (1989): 89-94.

45. Cui Z, Yu B, Xu C, Li X, Song J, Ouyang $\mathrm{H}$, Chen L. Unreamed intramedullary nailing versus external fixation for type IIIA and IIIB open fractures of tibia shaft: a subgroup analysis of randomized trials. $\mathbf{J}$ Nov Physiother. 2013;3:2

46. Kaftandziev, I., Pejkova, S. \&Saveski, J. Operative treatment of III grade open fractures of the tibial diaphysis. Prilozi.
2006; 27, 121-131.

47. Edwards, C. C., Simmons, S. C., Browner, B. D. \& Weigel, M. C. Severe open tibial fractures. Results treating 202 injuries with external fixation. Clin Ortho Relat Res. 1988; 98-115.

48. Keating, J. F., Gardner, E., Leach, W. J., Macpherson, S. \&Abrami, G. Management of tibial fractures with the orthofix dynamic external fixator. $J R$ Coll Surg Edinb. 1991; 36, 272-277.

49. Fang, X., Jiang, L., Wang, Y. \& Zhao, L. Treatment of Gustilo grade III tibia fractures with unreamed intramedullary nailing versus external fixator: a metaanalysis. Med SciMonit. 2012; 18, RA4956.

50. Hutson, J. J. et al. Mechanical failures of intramedullary tibial nails applied without reaming. ClinOrthopRelat Res. 1995; 129 137.

51. Court-Brown, C. M., Will, E., Christie, J. $\&$ McQueen, M. M. Reamed or unreamed nailing for closed tibial fractures. A prospective study in Tscherne C1 fractures. J Bone Joint Surg Br. 1996;78, 580-583.

52. Alberts, K. A., Loohagen, G. \& Einarsdottir, H. Open tibial fractures: faster union after unreamed nailing than external fixation. Injury. 1999; 30, 519523.

53. Inan, M., Tuncel, M., Karaoglu, S. \& Halici, M. Treatment of type II and III open tibial fractures with Ilizarov external fixation. Acta Orthop Traumatol Turc. 2002; 36, 390-396.

54. Paley, D. Problems, obstacles, and complications of limb lengthening by the Ilizarov technique. Clin Orthop Relat Res.1990; 81-104. 